Instructions for authors, subscriptions and further details:

\title{
http://mcs.hipatiapress.com
}

\section{Cosmopolitan Revolutionaries: Masculinity, Migration, and Gender Performativity in Latin American London}

Natalie Araújo ${ }^{1}$

1) La Trobe University (Australia)

Date of publication: February $21^{\text {st }}, 2020$

Edition period: February 2020 - June 2020

To cite this article: Araújo, N. (2020). Cosmopolitan Revolutionaries: Masculinity, Migration, and Gender Performativity in Latin American London. Masculinities and Social Change,9(1), 1-27. doi: 10.17583/MCS.2020.4376

To link this article: http://doi.org/10.17583/MCS.2020.4376

PLEASE SCROLL DOWN FOR ARTICLE

The terms and conditions of use are related to the Open Journal System and to Creative Commons Attribution License (CC-BY). 


\title{
Cosmopolitan Revolutionaries: Masculinity, Migration, and Gender Performativity in Latin American London
}

Natalie Araújo

La Trobe University (Australia)

\begin{abstract}
This article explores the relational dynamics by which a group a young Colombian men strategically construct and perform masculinity within context of London. It focuses on quotidian experiences and seeks to move beyond stereotypical narratives of masculine "loss" or "adjustment" relating to machismo. The article demonstrates how "traditional" hegemonic norms are resourced as constitutive elements in the articulation of new modalities of gendered orientation. It observes that with migration Latin American men are often placed under contradictory pressure to both conform to and subvert cultural stereotypes of machismo and hegemonic masculinity. In this case study young Colombian migrants are seen to harness vernacular cosmopolitanism as an important moral orientation through which to creatively rearticulate machismo and dynamically reframe their subjectivities in ways that meaningfully engage with their life predicaments. What emerges are expressions of a subjectivity referred to here as the 'cosmopolitan revolutionary'. This is a performative orientation that encourages the expression of masculine authority and decisiveness while also emphasizing antiauthoritarian and egalitarian principles of positive reciprocity and worldly care.
\end{abstract}

Keywords: cosmopolitanism, migration, masculinity, diaspora, machismo 
MCS - Masculinities and Social Change Vol. 9 No. 1 February 2020

pp. 1-27

\title{
Revolucionarios Cosmopolitas: Masculinidad, Migración y
}

\section{Performatividad de Género en el Londres Latinoamericano}

\author{
Natalie Araújo \\ La Trobe University (Australia)
}

\begin{abstract}
Resumen
Este artículo explora la dinámica relacional mediante la cual un grupo de jóvenes colombianos construye y realiza estratégicamente su masculinidad dentro del contexto de Londres. Se centra en la experiencia cotidiana y busca ir más allá de las narraciones estereotipadas de la "pérdida" o "ajuste" masculino relacionado con el machismo. El artículo demuestra cómo las normas hegemónicas "tradicionales" cuentan con recursos como elementos constitutivos en la articulación de nuevas modalidades de orientación de género. Observa que con la migración, los hombres latinoamericanos a menudo se ven sometidos a una presión contradictoria para conformarse y subvertir los estereotipos culturales del machismo y la masculinidad hegemónica. En este estudio, se considera que los migrantes colombianos aprovechan el cosmopolitismo vernáculo como una orientación moral importante a través de la cual rearticular creativamente el machismo y reformular dinámicamente sus subjetividades de manera que se involucren significativamente con sus dificultades de la vida. Lo que emerge son expresiones de una subjetividad a la que se hace referencia aquí como el "revolucionario cosmopolita". Esta es una orientación performativa que fomenta la expresión de la autoridad y la decisión masculinas, al tiempo que enfatiza los principios antiautoritarios e igualitarios de reciprocidad positiva y cuidado mundano.
\end{abstract}

Palabras clave: cosmopolitismo, migración, masculinidad, diáspora, machismo 


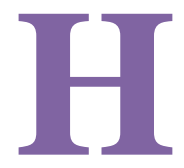

istorically taken for granted as the normative subject of migration (Wojnicka \& Pustulka, 2017, p. 89), the rise of feminist critique and the growth of masculinities studies have spurred a recent surge in research focusing directly on the life experiences of migrant men and masculinities (Charsley \& Wray, 2015; Donaldson, Hibbins, Howson \& Pease, 2009; Hearn, 2015). Where Latin Americans are concerned, focusing on notions of machismo, analyses have highlighted narratives of masculine adjustment, resistance or loss as occurring as a result of the "impact" of moving from "traditional" to "modern" gender regimes, often in contrast to relative feminine gain (for critical discussions, see McIlwaine, 2008; Torres, Solberg \& Carlstrom, 2002). This article contributes to emerging ethnographic scholarship that aims to move beyond these viewpoints by highlighting the creative plurality of Latin American masculinities, especially as expressed and performed in everyday life (Brigden, 2018; Del Aguila, 2014; Pérez \& Stallaert, 2015; Walter, Bourgois \& Loinaz, 2004). Drawing on Connell's influential concept of 'hegemonic masculinity' (Connell, 1995; Messerschmidt, 2018), here it is observed that with migration Latin American men are often placed under contradictory pressure to both conform to and subvert cultural stereotypes of machismo and hegemonic masculinity. Rather than necessarily resulting in 'masculine compromise' (Choi, 2019), however, here young male Colombian migrants living in London harness vernacular cosmopolitanism (Bhabha, 1996; Werbner, 2006) as an important resource through which to rearticulate machismo, dynamically reframing their subjectivities in ways that meaningfully engage with their life predicaments. What emerges are expressions of a subject position referred to here as the 'cosmopolitan revolutionary,' a performative orientation that encourages the expression of masculine authority and decisiveness while also emphasising antiauthoritarian and egalitarian principles of positive reciprocity and worldly care.

Commenting on the allure of London as a site of Colombian migration, MacIlwaine (2005, p. 7) has noted: 


\section{Natalie Araújo - Cosmopolitan Revolutionaries}

London represents a city of hope, disillusion and ultimately, a source of huge contradictions for its growing Colombian community. Acknowledging the difficulties in estimating the size of the population in light of the unregistered and illegal nature of much Colombian migration, the community is thought to number between 50,000 and 200,000 people and probably around 150,000 . Yet, despite the growth and increasing interest as one of the city's "new migrant groups", little is still known about how the community lives and functions.

This article draws from just under two years ethnographic anthropological fieldwork that sought to understand the hopes, contradictions and life experiences of Colombian migrants in London during a period of immigration reforms and increasing criminalisation of irregular migration. Myself a USborn Colombian woman and recent migrant to London, during this time and as part of my research methodology, I volunteered as an immigration and wellbeing advisor at a number of Latin American and migrant non-profit organisations and community groups. As part of my work within these organisations, with full disclosure of my position as researcher, and with consent of organisational leadership and participants, I documented the impact of changing immigration policy, leadership regimes, and public discourses on the organisations and individuals within them. To this end, in the broader project I utilised a number of qualitative research methods including participant-observation, the production of fieldnotes, analysis of visual, archival, and document-based sources, and the use of audio-visual recordings. I conducted both focus groups and individual interviews and collected life histories of research participants, often carrying out numerous interviews with participants over weeks and months.

These organisations included the site of this study, a busy migrant-run organisation, referred to here as the Latin American Refugee Association (LARA, a pseudonym). The events described in this article revolve around the crisis-fuelled election for the Managing Committee of a largely Colombian subsidiary youth organisation, referred to as Vision Revolution (VR, also a pseudonym). Specifically, I draw on the life histories and a public declarations 
of the three official candidates for the position of Chair of the Managing Committee of VR: Luis Calderon, Alejandro Diaz, Daniel David Sierra. This article utilises fieldnotes from participant-observation, life history and semistructured interviews, and analysis of transcribed recordings. It should be noted that many of participants in this research, including the majority of the men whose life stories are explored here in depth, and unnamed members of the organisation whose opinions are expressed, were either undocumented migrants or in situations of pronounced precarity - for example, in the process of applying for more secure migration status, working outside of the parameters of their visas, or otherwise experiencing self-identified challenges due to migration status. Out of respect for the vulnerabilities experienced by those whose lives are impacted by precarious immigration status, and in line with prevailing ethical standards, the names of research participants have been changed. Given the involvement of research participants in the leadership of the organisations in which fieldwork was conducted, I have also used pseudonyms for the names of the organisations.

\section{Moving Machismo: Latin American Masculinity in Migrant Context}

Discussions of male migration from Latin America often rest on assumptions about 'machismo', a term routinely used to describe stereotypical Latin American masculinity. A product of the "interplay of cultures under colonialism" (Connell, 1995, p. 198), machismo typically describes generalised patterns of male characteristics, including bravado and status seeking, aggressive display, dominating oppression of women, emotional immaturity and promiscuity (Arciniega, Anderson, Tovar-Blank \& Tracey, 2008; Basham, 1976; Torres, Solberg \& Carlstrom, 2002). While sometimes highlighting positively the sex appeal and virility of "Latin lovers", machismo is more often used negatively to suggest a moral failure within Latin American masculinity, and as such was defined early in popular discourse and academic literature as a "cult of virility" (Stevens, 1965). Machismo has more recently been interpreted as a form of masculine prestige (Gutmann, 1996) synonymous with hegemonic hyper-masculinity - hyperbolically, a 


\section{Natalie Araújo - Cosmopolitan Revolutionaries}

"superman of the multitude" complex (Paredes, 2003, p. 329) — and, as a corollary to such essentialist stereotypes, male oppression of women (Ramirez, 2008). Given these connotations, academics have referenced machismo in providing cultural and socio-psychological explanations for wide range of concerns relating to male behaviour, in Latin American and abroad, especially relating to domestic violence and substance abuse (Flake \& Forste, 2006).

Academic reference to "traditional" machismo has similarly become shorthand for perceived dysfunctions and moral inferiority in Latin American masculinity, including in contradistinction to what are figured as "modern" Western counterparts (Gutmann, 2004; Mcllwaine, 2010). Research in transnational settings has reinscribed these "otherings" through insidious subtexts that posit Latin Americans as struggling to resist or adjust within what are framed as more "progressive" or "enlightened" social contexts (e.g. Ramirez, 2009; and for an ethnographic critique, Brusco, 2010), thereby reflecting a discursive "denial of coevalness" (Fabian, 2002). By definition of machismo, the pervading message has been that in migrating to Western Europe and North America Latin American become anachronistically and morally 'out of place,' and must find a way to conform to host gender regimes or somehow fail to succeed as "modern" men.

Clearly machismo does not simply describe ways of male being, but also provides 'a way of evaluating or judging' masculine expression (Hernandez, 2012, p. 99). Indeed, the term is routinely used in migrant contexts such as London to describe the actions and orientations of men (McIlwaine, 2010, p. 287), and reflections on the effectiveness of such stereotypes to the migrant context were critically engaged with by research participants. Indeed, my research findings suggested a more complicated picture than that presented by McIlwaine (2010, p. 287-288) — of men positively reinforcing and women criticising machismo behaviour. As one of my male research participants suggested in the course of an interview, "machista behaviour wouldn't work here in London. It belongs back home". Despite such assertions, however, hegemonic ideals of masculinity and machismo were more generally and sometimes contradictorily reinforced, including by "women who may respect 
and value "true macho" characteristics because they also benefit from them" (Brusco, 2010, p. 86). Another participant, Susana maintained during interview about relationships, for example, that she "wouldn't tolerate machista bullshit", yet also wished that her partner should "act like a real man" by taking the lead in decision-making, defending her honour, and providing for her materially, all qualities of positive machismo.

Usage was, however, significantly gendered with women typically employ the adjectival machista to describe egotistical or authoritarian actions amongst men. By contrast, being "a real macho" was not always seen by men as advantageous or enabling, but as a burden of impossible expectation, especially in the difficult circumstances of undocumented migration. Here, any masculine advantage assumed to derive from machismo "back home" instead appeared as a double bind of constraint, particularly for men who were unable or unwilling to "live up to" associated expectations in everyday life. Further, suggestive of the fluidity by which machismo and its meanings are applied in everyday talk, it was not only men who were described as macho, but also self-confident, 'pushy' or subversive women, almost entirely in explicitly negative terms. Instructively, an analysis of machismo that includes such cross-gender usage reveals that while morally ambiguous behaviours are relatively accepted if not expected for men, women are by contrast typically consigned on either/or terms, as 'good' women who act within the norms of gendered expectation or as socially and therefore morally subversive or abject.

Discourses of machismo that reduce idealised masculinity to a set of narrowly and negatively conceived parameters fail to recognise the diversity of male expression that plays out in real life. Nevertheless, such idealisations, whether positively or negatively conceived, do inform everyday gendered expression. In this way machismo reflects Connell's conception of "hegemonic masculinity," including in that the most visible bearers of that form may not represent the most powerful individuals in a given social context (Connell, 1995, p. 77). Indeed, considering their stylisation and proliferation in popular culture, it may be rare if not impossible to locate ideal living exemplars at all. Hegemonic masculinities -and machismo- rather represent ideological yardsticks for identity formation and evaluation, providing 


\section{Natalie Araújo - Cosmopolitan Revolutionaries}

important reference points for both male and female actors (Connell \& Messerschmidtt, 2005); a measure against which all gender expressions are produced and judged. As the following case study shows, men both act out and act against dominant narratives of masculinity, working with them both consciously and unconsciously in ways that articulate with their life predicaments and goals.

\section{Contesting Migrant Masculinity}

Before discussing the election in detail, let me first draw upon the life histories I gathered from each man, presenting a biographical sketch by which to better examine the relational complexity by which their expressed versions of masculine identity were articulated. Indeed, on their own, each presents a rather different picture of masculinity within the context of migration to London. On my first day as a LARA volunteer, Luis Calderon, a paid coordinator of the organisation, shared his migration story with me, condensed here from interview transcripts and fieldnotes. Luis was an energetic organisational leader, but also considered by many to be reckless, selfseeking, authoritative and "emotionally restrictive and controlling" -what may be considered stereotypical "traditional machismo" (Torres, Solberg \& Carlstrom, 2002, p. 163) At the same time he fitted the orientation I describe as "cosmopolitan revolutionary," expressing a deep care for the plight of fellow migrants alongside worldly knowledge and experience. Confirming by way of narrative reversal McIlwaine's (2010, p. 287-288) assertion that machismo changes as it travels, his personal history suggests further complexity, and indeed a "flexibility" in gendered orientation (Torres, Solberg \& Carlstrom, 2002) that would belie both of these categories.

Luis moved from Manizales as a young child and enrolled in private schools in Cali where his mother opened a small business. He described his childhood as idyllic, but claimed that his perceptions of home changed radically as he grew older. As an adolescent, his view of Cali and by extension Colombia was impacted by a series of widely reported political scandals in the mid and late 1990s, including especially an allegation by future Colombian 
president Andres Pastrana and by US government officials that President Ernesto Samper's political campaign had been funded by leaders of the Cali drug cartel (Dugas, 2001). Recalling his late teenage years from the distance of over fifteen years, Luis claimed that as a teenager he felt increasingly disillusioned by what he perceived as growing social inequity in Cali, and actively pursued an educational opportunity in Cuba. There he became, as he put it, "versed in the language and politics of revolution". Returning to Colombia a year later, he was eager to actively help make positive social change yet convinced that he could not do so from within the state. After assessing possibilities in Ecuador, Venezuela, and the United States - each dismissed for economic or political reasons - Luis moved to London with his mother, where he initially stayed in the home of an uncle. Following his uncle's lead, Luis became involved with migrant organisations.

At the time that he shared this narrative Luis was over thirty, a permanent UK resident, long-term London inhabitant, and committed Marxist who had not returned to Colombia in over ten years. Describing his experiences, Luis positioned himself as a life-long crusader against injustice, routinely framing his separation from Colombia in terms of sacrifice and political necessity. Months later, by which time Luis was not only accustomed to my presence as a researcher but also aware of my interests in and personal connections to Colombian artistic and folk culture, he shared another version of his migration experience. The differences between these narratives is telling, not only relating to contested ideas of machismo, but more specifically for demonstrating how individuals may assume and move between a plurality of masculine identity positions. Such instances signal the presence of complex nuances of masculine identity, such that analyses reliant on singular narrative renditions of gendered losses or gains would foreclose. Luis, it could be said, was more or less macho depending on the telling. Likewise, and accordingly, depending on context and expediency he was able to express a position of either gain or loss of masculine status depending on which version of migration experience he chose to highlight.

As we walked to a local Colombian restaurant during a lunch break from work at LARA, Luis explained how he had attended dance schools during 


\section{Natalie Araújo - Cosmopolitan Revolutionaries}

adolescence and later trained for a national dance troupe. One dance academy neighboured a local military academy and cadets routinely shouted homophobic slurs at Luis and friends, threatening the boys and calling them by the derogatory Spanish term for homosexuals, "maricons". As Luis described the taunting his cheeks became visibly flushed and his voice grew louder. People such as the abusive cadets, he observed, would grow up to defend and lead Colombia, and this, to Luis, represented everything that was wrong with the nation. His disgust for such behaviour fuelled a deep resentment, not only against those who had victimised him directly but against what he perceived as a social system that re-enforced the legitimacy of their views and glorified their militaristic, masculine identities. Though Luis considered himself to be, in his own words, a "genuine macho", and as much a "real man" as the cadets, he was aware that his artistic pursuits placed him outside of the boundaries of normative masculinity in the eyes of most male peers. When those same alienating characteristics enabled him to travel to Cuba, Luis began to interpret his own isolation as symbolic of larger systemic problems in Colombian society. For this reason, he explained, rather than returning to Colombia he chose to move to London. There, like many younger migrants, he felt he would find a context for freedom of expression not available "back home".

Like Luis, Alejandro Diaz, VR's de facto co-Chair before the election and a LARA volunteer, eschewed normative machismo in a rather different way. Reflecting Wilkins' (2009) study of "masculinity dilemmas" amongst Goths and Christians in conservative USA, in our conversations he also ameliorated any potential masculine loss through infusing his migration narrative with discourses of political struggle. The son of a reasonably well-off agricultural manager, Alejandro was sent to be educated in Medellin. There he lived in an apartment with his mother and younger sister. As a teenager, Alejandro explained in interviews, he became active in a subversive subcultural scene that had begun to attract unwanted attention from representatives of the infamous Colombian Departamento Administrativo de Seguridad (DAS). Alejandro claimed that he was approached and threatened on several 
occasions by DAS operatives on account of his lifestyle and fashion choices. As Alejandro explained to me shortly after we became acquainted:

\begin{abstract}
My friends and me, we would dress crazy and keep our hair long. We had our own thing going on. You know what everyone else looks likejeans, buttoned up shirts, clean - and then there was me with crazy piercings and colours in my hair and going to crazy parties. I definitely attracted attention.
\end{abstract}

As he described, when a family friend approached Alejandro's father to warn that there were rumours that Alejandro's life was in danger, the family asked for no proof and immediately prepared to leave the country. Though intimidation from State agents might have been sufficient grounds for an asylum application, Alejandro and his family were all too aware that such threats were impossible to document. Instead of risking a failed asylum attempt, they arranged for a local authority to produce registry papers for a grandparent alleged to have been born in France, thus allowing the family to apply for EU passports. (Subsequent conversation revealed that the birth certificate was a falsified, a widespread method of manipulating immigration systems amongst my research participants). Though their new passports were French, the family decided to settle in London, not only for social and economic opportunity, but also, Alejandro maintained, because it was believed that the children would be better off in what his mother, seemingly taking a cue from the London Mayor's Office, had called, "the diverse and cosmopolitan capital". It was out of this personal experience of oppression in Colombia that Alejandro, like Luis, explained his involvement in LARA and VR.

Alejandro was unemployed and homeless during the time of my research, and for much of my fieldwork slept in the VR premises. In this way, while those with homes to go to departed at the end of the day for other corners of the city, he along with several other men would stay behind, unrolling dance mats and sleeping bags hidden in drums, transforming the youth centre into a shelter. At night, he explained, he padlocked the door from the inside with a 


\section{Natalie Araújo - Cosmopolitan Revolutionaries}

chain that he then threaded through a hole in the door to give the room the outward appearance of being secured. However, importantly, while it might be supposed that this predicament of homelessness and organisational dependence would present a compromise to his masculine identity, by attaching it to a narrative of political struggle Alejandro was able to use it to the opposite effect. Like Luis, Alejandro's narrative imaginary revolved around themes of self-sacrifice and moral integrity. He maintained that his willingness to lock himself within the VR premises overnight was an act of care for the organisation and its fellow members.

In contrast to Luis and Alejandro, or Daniel David Sierra, easy access to the "patriarchal dividends" of hegemonic masculinity (Connell, 1995) were confounded by inequalities of race and class. Like Luis and Alejandro, Daniel's journey to London had been motivated by violence. Unlike the majority of his VR and LARA counterparts, however, who hailed from elite and middle class backgrounds, Daniel had been born into poverty and domestic instability; the son of an Afro-indigenous mother who, aged just fourteen at the time of his birth, had survived in abusive relationships necessitated by multiple internal displacements in Colombia. Though intelligent and academically minded, Daniel's athleticism offered the best opportunity to move beyond these circumstances, ultimately resulting in a scholarship to a private school. Even so, Daniel believed that were he to achieve sporting success, his socio-economic and ethnic identity would continue to limit his potential in Colombia due to what he saw as an endemic culture of racial and class discrimination (see Wade, 1995). As he explained to me:

Sport gave me opportunities I never could have dared to imagine. I was able to learn from great teachers and better myself in ways I never would have been able to otherwise. But there is a limit to what I could achieve in Colombia. People were always going to see me the way they saw me, you know. They look at me and they just see a poor black man. 
At the age of fifteen, Daniel arrived alone in London on a tourist visa, ostensibly to visit an acquaintance of his mother. Though proud of his personal heritage, he avoided mingling with fellow Colombians, preferring to spend his time with immigrants from what he described as "more established groups" who were, in his words, "beyond the bullshit of identity politics" namely, Afro-Caribbean migrants. Seven years later, frustrated by the ways in which his undocumented immigration status prevented him from pursuing higher education or traveling beyond what he described as the increasingly "limited horizons of the city", he proposed to and quickly married his girlfriend, a first-generation Palestinian refugee who had attained British citizenship through asylum. Daniel repeatedly assured me that his marriage was not "one of those", by which he implied a marriage for a visa. Though he also acknowledged that while he loved his wife, their relationship was strategic. Though still officially married at the time of my initial interviews, Daniel and his wife had only resided together for a matter of months in the course of their years' long marriage. Instead, he pursued relationships with two other women, both of whom were Colombian, which gradually pulled him into Colombian social circles. Ultimately, it was his fear that his wife would divorce him and compromise his opportunities for legal status that spurred Daniel's involvement in LARA, then VR.

The experiences of these three men are not exhaustive of all Colombian males within the organisations studied, let alone residing in London as a whole. They do however reflect in their differences and similarities the heterogeneous experiences that brought male members of LARA and VR to each other, and the circumstances of how the merged narratives of masculinity and cosmopolitanism that lie at the centre of this article emerged. While diverse, they do not represent neatly distinguished identities, but rather are interconnected by forces that shape a particular experience of the state, citizenship, masculinity and mobility. Indeed, this sense of a shared experience of migration, globality, disruption, and the denial of masculine legitimacy was relevant to each in that it positioned them toward similar patterns of self-expression and behaviour. Importantly, as explored further below, their experiences predisposed these men towards common narratives 


\section{Natalie Araújo - Cosmopolitan Revolutionaries}

and strategies in which ideas of cosmopolitanism formed an important central focus of articulation.

\section{The Election: A Case Study in Relational Masculinities}

The election of the Board of Management of Vision Revolution illustrates these patterns. According to informally agreed principle, the youth organisation Vision Revolution (VR) employed a non-hierarchical structure whereby individual members maintained equal rights and decision-making powers. However, considering the importance of gaining and auditing funding, and managing interactions with external bodies such as the local government, a Managing Committee was a necessary practicality for the organisation. Even so, in their everyday discourse VR participants resisted the suggestion that the organisation comprised a hierarchical structure or had officially designated "leaders". Instead, Committee members were presented as "representatives", ambassadors whose role it was to express the collective will of the group's members, including by having the capacity to negotiate and sign contracts on behalf of the group and as signatories on Vision Revolution's bank accounts. While on one hand Committee membership exposed individuals to liability -as legally responsible to the Borough Council for actions taken on behalf of the group, for example- on the other it presented opportunities for individuals to assert themselves and affect changes in ways other "ordinary" members could not. Despite assertions to the contrary, that this presented something of a contradiction to the informal egalitarian ethos was not lost on active VR members.

In the days before the Committee election, I observed numerous workshops and private discussions among the approximately forty VR members on who was best qualified to "lead the organisation". Notably, though outnumbering men in general membership by a ratio of approximately 3 to 2, no female member was put forward as a viable candidate for any position other than secretary. Perceived by members as a primary supporting role concerned with recording rather than directing decision-making, this gendering conformed to what is in Latin America and elsewhere a stereotype 
of secretarial work as subordinate "women's work" (Wichoroski, 1994), and therefore might be seen to reflect "traditional" gender roles whereby women care and men lead. Further, it became apparent that not simply men, but more specifically particular kinds of men were seen as more appropriate to exercising effective organisational leadership than others. Rather than sharing a single form, however, and in line with Connell and Messerschmidtt's (2005) argument concerning the fluidity and potential contradictions of hegemonic masculinity, each articulated the stereotype of machismo in idiosyncratic yet relationally overlapping ways.

On the day of the election, four candidates had emerged for the central position of Chair. This included two existing de facto co-Chairs, Luis Calderon and Alejandro Diaz, and two new candidates, Daniel David Sierra and Hernan Jimenez, the latter being an indigenous Colombian man in his late $40 \mathrm{~s}$, perceived as the group's elder, who almost immediately withdraw his candidacy. At the meeting, having been provided an opportunity to address members prior to voting, each man's argument as to why he should be elected centred on the affirmation of a particular version of masculinity, and equally on the critique of his competitors' own masculine personas. Here, far from simply representing a negative drawback or anachronistic constraint, the situation of machismo within Latin American London emerged as an important point of contrast and legitimacy.

As an existing co-Chair, and paid coordinator of the umbrella organisation, Latin American Refugee Association, the first man, Luis Calderon, was an ambitious and experienced leader. He was also widely perceived by other members of VR as "brash, charismatic and energetic". However, against these common machismo traits, Luis liked to highlight the extent to which he specifically did not conform to stereotypes "back home" in Colombia, for example as a self-professed supporter of women's rights and by pursuing such endeavours as ballet dancing. The second man, Alejandro Diaz, had likewise subverted stereotypical machismo in Colombia through involvement in gender-subversive subcultural activity. He was less explicitly macho than Luis in terms of his presentation of self within the organisational context. Even so, he too sought to ameliorate this by engaging in discourses of political struggle, 


\section{Natalie Araújo - Cosmopolitan Revolutionaries}

particularly through reference to his own migration narrative. By contrast to both of these men, Daniel David Sierra was noted by research participants to exhibit many positive machismo qualities, especially by being quick-witted and intelligently outspoken, physically powerful and athletic, and for having developed a reputation for being sexually virile. This was, however, compromised by the fact of his financial dependence on a woman, his wife, and more especially through his status as an Afro-Colombian migrant of low socio-economic background. Despite such contrasts vis-à-vis hegemonic masculinity and machismo, each man fitted the orientation of "cosmopolitan revolutionary", especially for engaging in anti-authoritarian political discourse relating to perceived persecution in London and Colombia.

None of these men outwardly conformed to the requirements of what might be described as "hegemonic masculinity" in Colombia or in London, at least not fully. Yet, within the context of the migrant organisations within which they worked and spent time, and from which they sought to draw masculine authority, in reframing their own particular migrant and "subaltern" masculinities in relation to aspects of cosmopolitan orientation they were able to strategically redefine the parameters by which their masculine identities were judged. In doing so, they thereby simultaneously appeared to subvert the "trap" of machismo even as they reified and sought to draw power from it. Importantly, when viewed as such on ethnographic terms, cosmopolitanism does not simply entail either descriptive device or personal orientation to the world, but is also a resource within broader relational strategies of engendering personal and group identity.

Mary Louise Pratt (1992, p. 6) has theorised "contact zones" as "the space in which people geographically and historically separated come into contact with each other and establish ongoing relations" - a space and time in which previously separated subjects become "co-present" and in which their narratives and experiences "intersect". Pratt (1992, p. 8) emphasises the asymmetrical relations of power that characterise such zones, as well as the "improvisational dimensions" of human interaction that take place within them. For the men and women of LARA and VR the physical premises of the organisations served as just such a contact zone - a space in which shifting 
configurations of gendered identity were dynamically expressed and contested. While each of the above renditions of masculine identity occurred through narrative self-reflection, the everyday expression of identity ultimately hinged on specific contexts of intersubjectivity. As a reflection of ideas concerning abstracted, globalised identity, cosmopolitan orientations here emerged as an important reference point for the formulation of identity. Against analyses that focus on male identity loss, through drawing creatively on images and narratives of cosmopolitanism the men at the centre of this chapter were able to assert diversely viable forms of masculine authority, including in a congruence between their own backgrounds, as based in some form of marginalisation or oppression "back home", and their experience of migration to London.

On the day of the election with members gathered and as I audio recorded the proceedings, the organisation's unofficial elder Hernan Jimenez began proceedings with a personal address to the group which included withdrawing his own candidacy. Hernan stated that he was not interested in achieving a position of formal responsibility, and instead encouraged his supporters to vote for his close friend and protégé, Alejandro. Turning the familiar New World/Old World dichotomy on its head, and setting the scene for the discussion that followed by highlighting the migration context, Hernan claimed that Alejandro was, as he put it, "a man capable of navigating this new world we're in". Listing Alejandro's virtues, Hernan drew attention to his "openness to the world", as demonstrated by an eagerness to establish connections between VR and other refugee groups in London, and awareness of "the importance of love and respect for other people above anything else".

Hernan's address engaged discourses of masculinity in important ways. First, in explicitly stating that Alejandro is a man who could navigate "this new world" - clearly understood to mean London- Hernan's appeal highlighted how Alejandro's masculine identity diverged from the Colombian hegemonic form, and in particular from that understood by "traditional machismo" (Torres, Solberg \& Carlstrom 2002, p. 163). In doing so, Hernan engaged as positive a construction of male identity that may be more typically seen from within the perspective of machismo to be negatively feminine. The 


\section{Natalie Araújo - Cosmopolitan Revolutionaries}

"right man" is one who is "open to the world", as well as "loving" and "respectful", and thus nurturing of human relationships —all significantly cosmopolitan principles. In this, Hernan implied that the necessary construction of masculinity in England could be perceived as softer than that of its Colombian counterpart. Finally, while advocating these interpretations Hernan avoided compromising his own position of masculinity, but rather reaffirmed it by dropping his own candidature and thereby distancing himself from Alejandro, a distinction made possible through an allusion to generational disparity and therefore closer temporal proximity to "tradition".

As Hernan spoke, Luis Calderon grew visibly upset. Though he restrained himself until Hernan concluded his remarks, the moment Hernan sat back down in his chair Luis lurched across the circle of chairs and toward Alejandro. Gesturing and raising his voice with each word, Luis stood inches from Alejandro's face, "Him? You want him to lead?"

As might be expected, the animosity expressed by Luis related to conflict that extended beyond the immediate context of the meeting. From the beginning my research, Luis and Alejandro maintained mutual disdain fed by Alejandro's relationship with a young woman who had previously dated the much older Luis, a relationship Alejandro, himself ten years her senior, categorised as "fucked" for being marred by gender-based violence and psychological abuse. As Alejandro explained to me, he had promised to treat her well, never to harm her in any way, and in explicitly stated contrast to Luis, to "act like a real man". Yet, while Alejandro disparaged the negative aspects of Luis's masculine identity - he didn't want to be "that kind of man" - he struggled to determine what exactly acting "like a real man" entailed in a positive, proactive sense. At the time, he confessed to me in an interview about his relationship and living situation:

I can't go home to my mama. I'm too old for that bullshit. I'm a man. And I can't move in with her [his girlfriend]. She's staying at someone else's place. Anyway, fuck, I'm supposed to take care of her. 
Alejandro had recently lost the latest in a string of temporary jobs and had been forced to give up his apartment. Luis, being aware that Alejandro was sleeping on the organisation's premises, drew upon this information as he confronted Alejandro. Calling Alejandro "lazy" and a "weakling", Luis alleged that Alejandro was neither capable nor trustworthy enough to be considered a potential leader. Further, pointing out that the organisation's use of the premises could be jeopardised if such Alejandro's activities were discovered, he added that Alejandro's actions presented a risk to every individual member by jeopardising a crucial communal resource. Then, in militaristic language that evoked the revolutionary politics of Latin America and alluded to shifting politics of migration and identity in the UK, Luis implored VR members to think beyond the organisation, stating dramatically that: "You need to understand; we are at war. We are fighting for ourselves and for the rights of people like us every place. We need warriors."

On the surface, Luis's outburst encapsulated many of the key attributes of machismo described above, including brashness, bravado and the spectre of violence. This was not lost on Alejandro. "Fuck you, man", Alejandro replied defiantly over Luis's voice. Then, calling him a "thug" and "bully", he responded by questioning whether the group could be represented and led by such a man who could not control his temper. The form of Luis's outburst only partially obscured its content. While Luis's aggressive assertion of masculinity appeared to conform to "undesirable" parameters of machismo, his positioning was ultimately novel. Presenting himself as a "warrior" fighting against the state structures of power and global class regimes - for the rights of what he would later refer to in specifically masculine terms in an interview as a "brotherhood of the oppressed", a category to which Luis believed that both he and his follow VR members belonged-Luis positioned himself as a border-crossing, cosmopolitan revolutionary. In his selfpresentation, Luis represented himself not a dominant, oppressor masculinity, but rather one defined by moral integrity, self-sacrifice, and sensitivity to the needs of vulnerable peoples everywhere. Yet, the language of this morally enlightened, cosmopolitan masculinity is that of fighting, war, and discord. As such Luis's masculine identity like his cosmopolitan identity, seemed 


\section{Natalie Araújo - Cosmopolitan Revolutionaries}

paradoxical, being incongruous with the characteristics that are assumed to define either orientation.

At this point, having remained quiet for duration of the meeting to this point, Daniel interjected. Waving his hands in the air and gesturing for calm, he explained:

This should not be about personal attacks. We're all in this together! We do have a fight, but it shouldn't be amongst ourselves. We have to fight for the rights of the people who come to VR, including people like Alejandro who don't have a place to sleep at night!

Adding an allusion to his ethnic difference to the other men, as well as his personal experience of being from lower rather than upper-middle class background, but also suggesting solidarity of experience, he added, "I know what it's like to be oppressed in Colombia. We have to fight for the rights of people everywhere!"

For all their individual contradictions, the versions of masculinity represented by Daniel, Alejandro and Luis shared important similarities. Indeed, all converged on the figure of the cosmopolitan but diverged in terms of their relation to the archetype of machismo. It was no coincidence that each of these central articulations of masculinity - Luis's as the warrior of the globally oppressed, Alejandro's as described by Hernan as "a man of the world", and David's as the oppressed minority with universal human empathy - were all framed through reference to broadly cosmopolitan ethics. In Luis's and David's case, that ethic is reflected in what is increasingly referred to in social sciences literature as "empathetic cosmopolitanism", an emotional and ethical engagement with human suffering and vulnerability across borders (see e.g.: Linklater, 2007; Beck, 2002). Likewise, Alejandro's projected masculinity was shaped in reference to an "openness to the world" and ability to nurture connection across human difference. To this extent, each man's presumed masculine identity was measured in accordance to indicators that correlated not only to his own moral or ethical position at a particular point in time, but to the perceived needs of the group as a whole. 


\section{MCS - Masculinities and Social Change, 9(1) 21}

Concurrently, each masculine assertion was contextualised not only on personal attributes, but more importantly through the relational masculine traits and material circumstances of each individual. Despite similarities, each man highlighted their own leadership qualities by way of presenting a moral contrast to what were presented as negative attributes identified in the other. The meeting in this sense represented a corollary to the Colombian cockfighting ring, wherein men are able to perform their masculinities in a very public competitive arena. However, these competitive exchanges were not solely restricted to defining masculine relations, as "primarily a way of structuring power among men to prove and validate one's masculinity to other men and oneself" (McIlwaine, 2010, p. 287). By rendering the orientation of "cosmopolitan revolutionary" as a legitimate alternative hegemonic ideal, they also worked to structure the organisation in such a way that excluded women from leadership, as well as from aspects of the organisation as a social space.

Bearing in mind the inherently unstable and encompassed situation in which gender was being articulated in this precarious migrant context, it is important to note that the meeting did not end favourably for any of the three candidates. Instead, after digressing into a protracted argument between the male protagonists and their supporters, the decision about leadership was delayed.

Several weeks later, following an exchange of physical threats amongst the men in question, as well as a conflict with the Council over theft from the shared kitchen and allegations of alcohol and drug use on the premises, VR came close to complete dissolution. At that stage, three women stepped in to overtake the day-to-day running of the organisation, an action that might be taken to suggest that women had a great deal more power within the organisation than the analysis of encompassed hegemonic masculinity presented here would allow. However, and according to that analysis, it can also be noted that their intervention also reflected the normative position of women as day-to-day organisational workers within what had, in the context of the meeting, become a more specifically public and official context. Indeed, as it happened, Luis not only remained signatory of the VR bank account, but, 


\section{Natalie Araújo - Cosmopolitan Revolutionaries}

as their relationships healed and day-to-day activities slowly reverted to the masculinised pseudo-public nature over the course of the next several months, he and Alejandro also ultimately regained their authority as leaders and ultimately resumed their roles as co-Chairs.

\section{Conclusion}

Sitting with me on a park bench shortly after the meeting, Daniel David Sierra interrupted our discussion about the ongoing leadership struggle to ask if I had read Hamlet. When I nodded affirmatively, Daniel leaned forward and exclaimed, "Then you should get it!" Leaning back against the bench, Daniel described how the situation of the men involved was not unlike those in Shakespeare's Hamlet, being victims of historical circumstance caught between a tyranny of competing interests, obligations, and cultural and ethical norms. Referring to Hamlet's famous "To be or not to be" soliloquy, Daniel went on to offer a brief critical insight into the central topic of article, "You've got to understand, the thing for these men is not to be or not to be, it's how to be." This article has taken Daniel's appropriation and subversion of Hamlet's famous existentialist question -one that transforms that question into an observation concerning masculine subjectivities - as a central analytic concern. In particular it has explored the ways in which a particular group of young Colombian men construct and perform masculinity within dynamic relations of power, amongst themselves and within a specific context of migration.

Much early literature on migrant Latin American masculinities focused on challenges to machismo and "traditional" masculinity brought about by engagement with "non-traditional" gender regimes, particularly in Western countries (see Torres, Solberg \& Carlstrom, 2002; Pease \& Crossley, 2005; Hondagneu-Sotelo, 1994). Focusing on quotidian experience and seeking to move beyond such stereotypical narratives as how migration entails "shifts from traditional to so-called modern" gender regimes, her work also presents a more complex picture (McIlwaine, 2010, p. 282). Her research approach, also taken here, reflects critical methodologies that advocate for a nuanced 
understanding of gender praxis, "not as a set of static structures or roles but as an ongoing process that is experienced through an array of social institutions from the family to the state" (Mahler \& Pessar, 2001, p. 442).

Focusing on relations between diverse men in migrant organisational context, research presented here adds further nuance to Mcllwaine's work, including the problematic assertion that Colombian migrant "machismo or hegemonic masculinity" is somehow less "flexible" than their feminine counterparts (2010, p. 282). Rather than assuming an inevitability to gender change, such as ultimately rests on a conceptual framework of radical cultural difference, the argument made here is that "traditional" hegemonic norms such as those associated machismo may themselves become a "constitutive element of migration" (Hondagneu-Sotelo, 2000, p. 117), doing so in creative articulation with other ideals, such as of cosmopolitanism.

Presented in the form of anti-authoritarian "cosmopolitan revolutionaries," elements of machismo were here seen to be infused cosmopolitanism representing not so much an idealistic philosophical orientation but a practically and strategically deployed tool for self-identification and actionin creative assertions of male agency. While based in counter-hegemonic discourse, it could be said that such practices simply reified hegemonic norms, especially vis-à-vis women. However, the appropriation of cosmopolitanism in terms of a vision of nationally unbounded possibility, empathy and worldly care also allowed these men to critically subvert and flexibly reformulate normative constructions of machismo, such that accorded with their new surroundings. Indeed, given personal inclinations and life situations, comprising non-traditional and non-hegemonic expressions positions of masculinity, each of the men at the centre of this case study would have found it difficult to attain positions of masculine authority "back home". Within the migrant context in which they now found themselves, however, through articulating ideals of both cosmopolitanism and hegemonic masculinity within personal narratives of marginalisation or oppression these men were able to redirect their subjectivities in such a way that accommodated contradictions inherent to their everyday life situations. 
24 Natalie Araújo - Cosmopolitan Revolutionaries

\section{References}

Arciniega, G.M., Anderson, T.C., Tovar-Blank, Z.G., \& Tracey, T.J.G. (2008). Toward a Fuller Conception of Machismo: Development of a Traditional Machismo and Caballerismo Scale. Journal of Counseling Psychology, 55(1), 19-33. doi: 10.1037/0022-0167.55.1.19 Basham, R. (1976). Machismo. Frontiers: A Journal of Women Studies, 1(2), 126-143. doi: 10.2307/3346074

Beck, U. (2002). The Cosmopolitan Society and its Enemies. Theory, Culture \& Society, 19(1-2), 17-44. doi: 10.1177/026327640201900101 Bhabha, H. (1996). Unsatisfied: Notes on Vernacular Cosmopolitanism. In L. García-Morena \& P.C. Pfeiffer (Eds.), Text and Nation: Crossdisciplinary Essays on Cultural and National Identities (pp. 191-207). Columbia, SC: Camden House.

Brigden, N. K. (2018). Gender Mobility: Survival Plays and Performing Central American Migration in Passage. Mobilities, 13(1), 111-125. doi: 10.1080/17450101.2017.1292056

Brusco, E.E. (2010). The Reformation of Machismo: Evangelical

Conversion and Gender in Colombia. Austin, TX: The University of Texas Press.

Charsley, K., \& Wray, H. (2015). Introduction: The Invisible (Migrant) Man. Men and Masculinities, 18(4): 403-423. doi:

10.1177/1097184X15575109

Choi, S.Y. (2019). Migration, Masculinity, and Family. Journal of Ethnic and Migration Studies, 45(1), 78-94. doi:

10.1080/1369183X.2018.1427562

Connell, R.W. (1995). Masculinities, Crows Nest, NSW: Allen \& Unwin. Connell, R.W., \& Messerschmidt, J.W. (2005). Hegemonic Masculinity: Rethinking the Concept. Gender \& Society, 19(6), 829-859. doi: $\underline{10.1177 / 0891243205278639}$

Del Aguila, E.V. (2014). Being a Man in a Transnational World: The Masculinity and Sexuality of Migration. New York, NY: Routledge. 
Donaldson, M., Hibbins, R., Howson R., \& Pease, B. (2009). Migrant Men: Critical Studies of Masculinities and the Migration Experience. New York, NY: Routledge.

Dugas, J.C. (2001). Drugs, Lies, and Audiotape: The Samper Crisis in Colombia. Latin American Research Review, 36(2), 157-174. Retrieved from www.jstor.org/stable/2692092

Fabian, J. (2002). Time and the Other: How Anthropology Makes Its Object.

New York, NY: Columbia University Press.

Flake, D.F., \& Forste, R. (2006). Fighting Families: Family Characteristics

Associated with Domestic Violence in Five Latin American Countries.

Family Violence, 21(1), 19-29. doi: 10.1007/s10896-005-9002-2

Gutmann, M.C. (1996). The Meanings of Macho: Being a Man in Mexico

City. Berkeley, CA: University of California Press.

Gutmann, M.C. (2004). Dystopian Travels in Gringolandia: Engendering

Ethnicity among Mexican Migrants to the United States. Ethnicities, 4(4),

477 - 500. doi: $10.1177 / 1468796804047470$

Hearn, J. (2015). Men of the World: Genders, Globalizations, Transnational Times. London, England: Sage.

Hernandez, J.C. (2012). Machismo: The Role of Chicano Rap in the

Construction of the Latino Identity. International Journal of Humanities and Social Sciences, 2(20), 98-106. Retrieved from

http://www.ijhssnet.com/journal/index/1350

Hondagneu-Sotelo, P. (1994). Gendered Transitions: Mexican Experiences with Immigration. Berkeley, CA: University of California Press.

Hondagneu-Sotelo, P. (2000). Feminism and Migration. The Annals of the American Academy of Political and Social Science, 571(1), 107-120. doi: $10.1177 / 000271620057100108$

Linklater, A. (2007). Distant Suffering and Cosmopolitan Obligations. International Politics, 44(1), 19-36. doi: 10.1057/palgrave.ip.8800156

Mahler, SJ., and Pessar, P.R. (2001). Gendered Geographies of Power: Analyzing Gender Across Transnational Spaces. Identiites 7(4), 44`-459. doi: 10.1080/1070289X.2001.9962675 
McIlwaine, C. (2005). Coping practices among Colombian migrants in London. London: Queen Mary, University of London.

McIlwaine, C. (2008). Subversion or Subjugation: Transforming Gender Ideologies Among Latin American Migrants in London, London, England: Queen Mary, University of London.

McIlwaine, C. (2010). Migrant Machismos: Exploring Gender Ideologies and Practices Among Latin American Migrants in London from a MultiScalar Perspective. Gender, Place, and Culture, 17(3), 281-300. doi: $\underline{10.1080 / 09663691003737579}$

Messerschmidt, J.W. (2018). Hegemonic Masculinity: Formulation, Reformulation, and Amplification. Lanham, MD: Rowman \& Littlefield. Paredes, A. (2003). The United States, Mexico, and Machismo. In M.C. Gutmann, F.V. Matos Rodriguez, L. Stephen, \& P. Zavella (Eds), Perspectives on Las Americas: A Reader in Culture, History, \& Representation (pp.329 - 341). Oxford, England: Blackwell.

Pease, B. \& Crossley, P. (2005). Migrant Masculinities: The Experiences of Latin American Migrant Men in Australia. Journal of Iberian and Latin American Research, 11(1), 133-140. doi:

$\underline{10.1080 / 13260219.2005 .10426813}$

Pérez, I. \& Stallaert, C. (2015). Male Domestic Workers and Gendered Boundaries among Latin American Migrants in Brussels. Revista Europea de Estudios Latinoamericanos y del Caribe, 98(69), 69-86. doi: 10.18352/erlacs.9981

Pratt, M.L. (1992). Imperial Eyes: Travel Writing and Transculturation. London and New York: Routledge.

Ramirez, J. (2008). Against Machismo: Young Adult in Mexico City. New York, NY: Berghahn Books.

Stevens, E.P. (1965). Mexican Machismo: Politics and Value Orientations, The Western Political Quarterly, 18(4), 848-857. doi: 10.2307/445889 Torres, J.B., Solberg, V.S.H., \& Carlstrom, A.H. (2002). The Myth of Sameness Among Latino Men and their Machismo. American Journal of Orthopsychiatry, 72(2), 163-181. doi: 10.1037/0002-9432.72.2.163 
Wade, P. (1995). Blackness and Race Mixture: The Dynamics of Racial Identity in Colombia. Baltimore, MD: Johns Hopkins University Press. Walter, N., Bourgois, P., \& Loinaz, M. (2004). Masculinity and Undocumented Labor Migration: Injured Latino Day Laborers in San Francisco. Social Science and Medicine, 59(6), 1159-1168. doi: 10.1016/j.socscimed.2003.12.013

Werbner, P. (2006). Vernacular Cosmopolitanism. Theory, Culture \& Society, 23(2-3), 496-498. doi: 10.1177/026327640602300291

Wichoroski, M.A. (1994). The Secretary: Invisible Labor in the Work World of Women. Human Organization, 53(1), 33-41. doi:

10.17730/hum.53.1.a1205q53j7334631

Wilkins, A.C. (2009). Masculinity Dilemmas: Sexuality and Intimacy Talk among Christians and Goths. Signs, 34(2), 343-68. doi: 10.1086/591087 Wojnicka, K., \& Pustułka, P. (2017). Migrant men in the Nexus of Space and (dis)Empowerment. NORMA, 12(2), 89-95. doi: $\underline{10.1080 / 18902138.2017 .1342061}$

Dr. Natalie Araújo is Lecturer in Anthropology, Department of Social Inquiry, La Trobe University, Melbourne, Australia.

Contact Address: Department of Social Inquiry, School of Humanities \& Social Sciences. La Trobe University. Melbourne (Bundoora) 3086. Social email: n.araujo@latrobe.edu.au 